\title{
NDEs and Satisfaction with Life
}

To the Editor:

I read with great interest Bruce Greyson's paper (1994) on neardeath experiences (NDEs) and satisfaction with life, a very needed research area. He wrote that the results-that NDErs were equally as satisfied with life as were nonexperiencers-were counterintuitive. Indeed they were, and I am not sure his explanations clarified all that made them so. I never believed that NDErs were messianic figures who would turn the world on the right track, as they are portrayed by some; but I expected something positive on the whole.

Could a bias in Greyson's sampling have contributed to the negative results? In my review (1994) of Kenneth Ring's book The Omega Project (1992), in which he sampled subjects from the membership of the International Association for Near-Death Studies (IANDS), I pointed out how unrepresentative that group is of the American population. Greyson's study also may be slanted by IANDS' unrepresentativeness. Maybe a new sample of unselected subjects, a sample referred by friendly physicians and nurses, would help clarify this point.

Let me emphasize that Greyson has put his finger on the right spot: we badly need clear insights into this area of research. I am just suggesting a little more. 


\section{References}

Greyson, B. (1994). Near-death experiences and satisfaction with life. Journal of NearDeath Studies. 13, 103-108.

Osis, K (1994). [Review of The Omega Project]. Journal of the American Society for Psychical Research, 88, 71-76.

Ring, K. (1992). The Omega Project: Near-death experiences, UFO encounters, and mind at large. New York, NY: Morrow.

Karlis Osis, Ph.D.

Chester F. Carlson Research Fellow Emeritus

American Society for Psychical Research

5 West 73rd Street

New York, NH 10023 